\title{
Electrochemical properties of exfoliated graphite/nickel/palladium/carbon fibers composite
}

\author{
P. Krawczyk ${ }^{1} \cdot$ T. Rozmanowski ${ }^{1}$
}

Received: 9 November 2018 /Revised: 1 December 2018 / Accepted: 5 December 2018 /Published online: 12 December 2018

(C) The Author(s) 2018

\begin{abstract}
The goal of this work was to design a alternative material for hydrogen sorption/desorption by electrochemical devices. The investigations were focused on $\mathrm{EG} / \mathrm{Ni} / \mathrm{Pd} / \mathrm{C}$ (exfoliated graphite/nickel/palladium/carbon fibers) composite. The deposition of carbon fibers differing in diameter and length over the EG/Ni/Pd significantly changes the electrochemical properties of the examined composite. SEM (scanning electron microscopy) analysis equipped with EDS (energy-dispersive spectrometer) detector revealed that external part of the investigated composite may involves palladium carbide.
\end{abstract}

Keywords Composite materials $\cdot$ Exfoliated graphite composite $\cdot$ Hydrogen sorption $\cdot$ Carbon fibers

\section{Introduction}

Composite materials based on transition metals exhibit excellent properties allowing their potential application in many fields, including chemical power sources. There are variety of methods allowing the inclusion of metal into the composite matrix. One of them is intercalation, which enables introducing an intercalate (e.g., metal compounds) within the graphite structure. Our previous works revealed that graphite intercalation compound with nickel chloride $\left(\mathrm{NiCl}_{2}-\mathrm{GIC}\right)$ and with nickel chloride, iron chloride, and palladium chloride $\left(\mathrm{NiCl}_{2}-\right.$ $\mathrm{FeCl}_{3}-\mathrm{PdCl}_{2}$-GIC) are electrochemically active towards the processes of hydrogen sorption/desorption [1,2]. The composite described in our last paper concerning the electrochemical properties of EG/Ni/Pd has a markedly different structure [3]. The sandwich type structure makes it more accessible to electrolytes, thus contributing to the increment in activity of reversible sorption of hydrogen.

This paper concerns the preparation and examination of the electrochemical properties of an $\mathrm{EG} / \mathrm{Ni} / \mathrm{Pd} / \mathrm{C}$ composite. The synthesized composite underwent electrochemical investigations in an alkaline solution by cyclic voltammetry. The morphology as well as the chemical composition of the EG/Ni/Pd/

P. Krawczyk

piotr.krawczyk@put.poznan.pl

1 Institute of Chemistry and Technical Electrochemistry, Poznan University of Technology, ul. Berdychowo 4, 60-965 Poznań, Poland
C surface was examined by scanning electron microscopy equipped with EDS detector.

The difference between the present investigations and the previous one is the appearance of external layer composed of carbon material. Our intention was to investigate the role of this layer in the processes of hydrogen accumulation. According to our best knowledge, the investigated composite can be regarded as a novel material, not investigated by others authors. Moreover EG/Ni/Pd/C composite has not been yet electrochemically investigated in the region of deep cathodic reduction.

\section{Materials and methods}

\section{Preparation of EG/Ni/Pd/C}

The entire process of EG/Ni/Pd/C preparation was carried out according to a three-step procedure. Firstly, exfoliated graphite (EG) was coated with a layer of $\mathrm{Ni}$ by electrochemical treatment in bath composed of $\mathrm{NiSO}_{4} \times 7 \mathrm{H}_{2} \mathrm{O}\left(140 \mathrm{~g} \mathrm{dm}^{-3}\right)$, $\mathrm{NiCl}_{2} \times 6 \mathrm{H}_{2} \mathrm{O}\left(5 \mathrm{~g} \mathrm{dm}^{-3}\right)$, and $\mathrm{H}_{3} \mathrm{BO}_{3}\left(20 \mathrm{~g} \mathrm{dm}^{-3}\right)$ using a constant current density of $20 \mathrm{~mA} \mathrm{~g}^{-1}$. As prepared EG/Ni underwent chemical reaction in $0.11 \mathrm{M} \mathrm{PdCl}_{2}$ dissolved in $1 \mathrm{M} \mathrm{HCl}$ to yield $\mathrm{EG} / \mathrm{Ni} / \mathrm{Pd}$ [3]. A carbon layer of $\mathrm{EG} / \mathrm{Ni} /$ $\mathrm{Pd} / \mathrm{C}$ composite was formed by thermal decomposition of acetylene by CVD method (chemical vapor deposition). This process was conducted for $30 \mathrm{~min}$. The flow rate of $\mathrm{C}_{2} \mathrm{H}_{2}$ was equal to $30 \mathrm{~cm}^{3} \min ^{-1}$ whereas $\mathrm{N}_{2}$ was adjusted to 
$100 \mathrm{~cm}^{3} \mathrm{~min}^{-1}$. It is known that thermal process of acetylene decomposition over the metal catalyst performed according to CVD method may leads to the formation of variety of carbon products. Besides the carbon fibers of a different length and diameter among the carbon products of the regarded process most often is amorphous carbon. This carbon should be considered as a unwanted product due to its low practical application. In order to remove the amorphous carbon, the products of CVD process were thermally oxidized to $\mathrm{CO}_{2}$ at $500{ }^{\circ} \mathrm{C}$ under air atmosphere.

\section{Electrochemical investigations}

The electrochemical measurements were performed with a three-electrode system, in which $\mathrm{EG} / \mathrm{Ni} / \mathrm{Pd} / \mathrm{C}$ was a working electrode, $\mathrm{Hg} / \mathrm{HgO} / 6 \mathrm{M} \mathrm{KOH}$ electrode served as a reference electrode (0.098 V vs. NHE), whereas a graphite rod played the role of counter electrode. The investigations were conducted at ambient temperature in $6 \mathrm{M} \mathrm{KOH}$ by cyclic voltammetry (CV) using an Autolab PGSTAT $302 \mathrm{~N}$ potentiostat/ galvanostat. The mass of the working electrode was equal to $30 \mathrm{mg}$. Voltammetric processes were performed with a scan rate of $10 \mathrm{mV} \mathrm{s}^{-1}$ within a potential range of $-1.2 \leftrightarrow 0.6 \mathrm{~V}$. During the selected cycles, when the electrode reached the potential of $-1.2 \mathrm{~V}$, potential scanning was automatically stopped for a certain time. After that, the potential scanning was continued in a positive direction. More details of the electrode preparation procedure can be found in our previous papers [1-3].

\section{SEM analysis}

The morphology and chemical content of the EG/Ni/Pd/C surface were studied by scanning electron microscopy (SEM) (S-3400 N, Hitachi) equipped with an EDS (Energy Dispersive Spectrometry) detector.

\section{Results and discussion}

\section{The morphology of EG/Ni/Pd/C composite}

Figure 1 displays SEM images of the synthesized EG/Ni/Pd/C composite. The carbon layer of the examined material comprises of tangled carbon fibers which differ markedly in length as well as diameter (see Fig. 1a). The comprehensive analysis of the presented images indicates that between the jumbled fibers, there are some particles probably not arising from the carbon. Owing to the reduced magnification (see Fig. 1b, c), one can observe bright patches of various shapes. Taking into consideration the brightness of these elements, it can be stated that they are associated with a material characterized by poor electrical conductivity. This means that
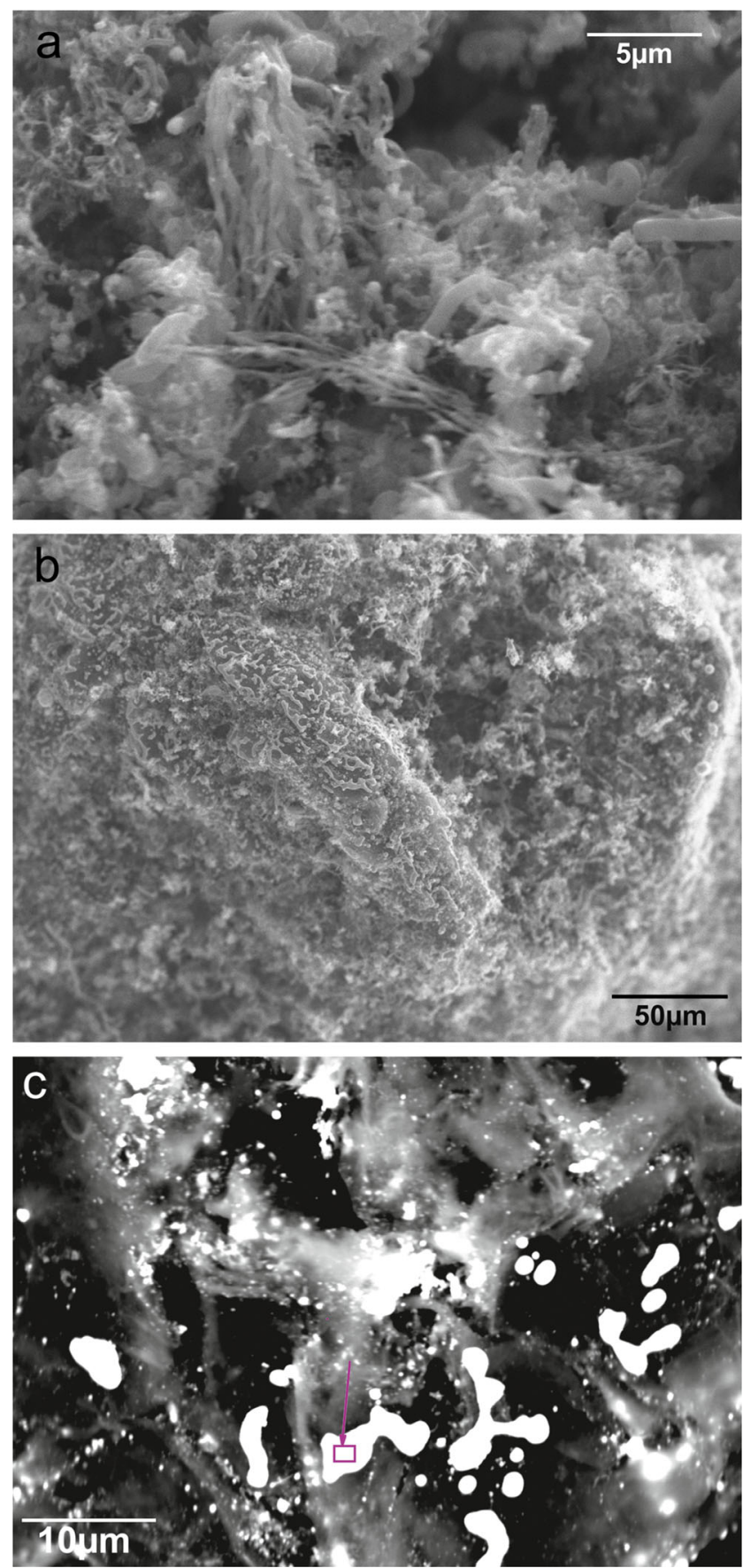

Fig. 1 SEM images of EG/Ni/Pd/C composite

these parts do not represent metal components of the investigated composite. EDS analysis of one of the bright patches (marked in Fig. 1c) showed that it consists of palladium (60.82 at.\%), carbon (36.22 at.\%), and nickel (2.96 at.\%). This result justifies the assumption that during the thermal decomposition of acetylene over $\mathrm{EG} / \mathrm{Ni} / \mathrm{Pd}$, the deposited carbon atoms penetrate into the palladium, yielding solid palladium carbide. It is known that the conductivity of palladium carbide is significantly lower compared to $\mathrm{Pd}$. This could explain the existence of some bright elements on the SEM 
images of EG/Ni/Pd/C composite (Fig. 1b, c). The process of carbon deposition over the palladium catalyst takes place when palladium is exposed to a flow of carbon containing gases at elevated temperatures [4-7]. In literature, one can find a number of theories describing the mechanism of carbon growth over metal catalysts. One of them postulates that carbon atoms formed on the surface of a catalyst diffuse through its structure and ultimately precipitate on the opposite side [8-11]. In such a case, the surface of the deposited carbon is often comprised of catalyst particles.

\section{Electrochemical sorption of hydrogen}

In the light of the presented results, it is reasonable to assume that the external layer of the $\mathrm{EG} / \mathrm{Ni} / \mathrm{Pd} / \mathrm{C}$ composite consists of carbon fiber and Pd particles containing incorporated carbon atoms appearing as palladium carbide [12]. The influence of the $\mathrm{EG} / \mathrm{Ni} / \mathrm{Pd} / \mathrm{C}$ contents on its electrochemical properties was examined on the basis of electrochemical investigations performed by cyclic voltammetry in an alkaline solution (see


Fig. $2 \mathrm{CVs}$ for $\mathrm{EG} / \mathrm{Ni} / \mathrm{Pd} / \mathrm{C}$ recorded with scan rate of $10 \mathrm{mVs}^{-1}$ in the potential range of $-1.2 \leftrightarrow 0.6 \mathrm{~V}$ (a) and CVs recorded after potentiostatic sorption of hydrogen for 15, 30, 45, 60, 180, and $900 \mathrm{~min}$ (b)
Fig. 2). During the first cycle, after starting the measurement from the rest potential of the electrode towards the more negative potentials, one can observe a wide cathodic wave with maximum at $-0.79 \mathrm{~V}$ (Fig. 2a). This effect illustrates the reduction of oxygen functionalities present on the carbon surface. The abovementioned cathodic wave partially overlaps the reactions associated with the potentiodynamic sorption of hydrogen. The latter reactions are depicted as an increase in current recorded on $\mathrm{CV}$ instantly before the change of polarization at $-1.2 \mathrm{~V}$. After the reversal of polarization, a barely visible anodic peak appears at around $-0.58 \mathrm{~V}$. This peak arises from the desorption/ oxidation of potentiodynamically sorbed hydrogen $[2,13]$. On further anodic scanning, when the potential reached a potential of $0.3 \mathrm{~V}$, the recorded current starts to grow, due to $\mathrm{Ni}^{2+} \rightarrow \mathrm{Ni}^{3+}$ transformation $[1,3]$. On backward scanning, at the potential of $0.33 \mathrm{~V}$, a small cathodic peak emerges, associated with the reverse reaction of $\mathrm{Ni}^{3+} \rightarrow \mathrm{Ni}^{2+}[1-3]$. For the second cycle, the slight diminution in intensity of effects corresponding to the reduction of oxygen functionalities and hydrogen sorption is observed. On further cycling, these effects are unchanged.

In order to check how the conditions of hydrogen sorption in $\mathrm{EG} / \mathrm{Ni} / \mathrm{Pd} / \mathrm{C}$ influences its electrochemical behavior, potential cycling was interrupted during the selected cycles at a potential of $-1.2 \mathrm{~V}$ for the potentiostatic saturation of hydrogen. The potential of potentiostatic sorption of hydrogen on the electrode made of $\mathrm{EG} / \mathrm{Ni} / \mathrm{Pd} / \mathrm{C}$ was limited to $-1.2 \mathrm{~V}$ to omit the risk of electrode damage due to intensive liberation of hydrogen. The first halt in potential scanning was performed during the 5th cycle for $15 \mathrm{~min}$. The consecutive operations of hydrogen sorption were proceeded during the 10th cycle $(30 \mathrm{~min}), 15$ th cycle (45 $\mathrm{min})$, 20th cycle (60), 25th cycle (180 min), and finally during the 30th cycle (for $900 \mathrm{~min}$ ) (see Fig. 2b). Taking into account the intensity of anodic effects attributed to hydrogen electrodesorption, it can be pointed out that the electrochemical activity of the investigated composite towards hydrogen sorption/electrooxidation is significantly higher compared to that noted during the potentiodynamic measurements (Fig. 2a). During the anodic scanning on all cyclic voltammograms shown in Fig. $2 \mathrm{~b}$ a wide wave with three maxima $(-0.58,-0.32$, and $-0.18 \mathrm{~V})$ appears in response to the potentiostatic sorption of hydrogen. The irregular shape of these effects indicates the multistep character of hydrogen electrodesorption. In other words, the achieved voltammograms suggest that hydrogen may be sorbed within more than one phase [1-3]. The intensity of these maxima are strongly influenced by the time of the preceding sorption. The electrochemical activity of $\mathrm{EG} / \mathrm{Ni} / \mathrm{Pd} / \mathrm{C}$ electrodes towards hydrogen desorption/electrooxidation gradually increases with prolongation of sorption time and, as expected, the highest level is reached after long lasting sorption $(900 \mathrm{~min})$. On the other hand, it should be emphasized that the relationship between the sorption time and electrocatalytical activity depicted as the intensity of the anodic wave is not linear. 
However, the activity level of the $\mathrm{EG} / \mathrm{Ni} / \mathrm{Pd} / \mathrm{C}$ composite is relatively high, but it appears to be significantly lower compared to that noted in our previous work for the EG/Ni/Pd composite [3]. This means that the appearance of the carbon layer on the surface of the EG/Ni/Pd composite did not improve its electrochemical activity towards the processes of hydrogen accumulation. A similar effect was observed previously for the $\mathrm{Ni} / \mathrm{Pd} / \mathrm{CNF}$ composite $[14,15]$. The deterioration of electrochemical activity was explained by the screening effect of the carbon film decreasing the active surface area of the palladium. It is reasonable to assume that the same reason is responsible for the discrepancy in the electrochemical activity of $\mathrm{EG} / \mathrm{Ni} / \mathrm{Pd}$ and $\mathrm{EG} / \mathrm{Ni} / \mathrm{Pd} / \mathrm{C}$. However, the plausible appearance of $\mathrm{Pd} / \mathrm{C}$ may also cause the lowering of the sorption capability of the $\mathrm{EG} / \mathrm{Ni} / \mathrm{Pd} / \mathrm{C}$ composite. By comparing the location of the anodic peaks, it is seen that the mechanism of hydrogen sorption/electrooxidation on $\mathrm{EG} / \mathrm{Ni} / \mathrm{Pd} / \mathrm{C}$ differs compared to the EG/Ni/Pd composite. For the former composite, a new peak at $-0.59 \mathrm{~V}$ appears. Contrary to $\mathrm{EG} / \mathrm{Ni} / \mathrm{Pd}$ and $\mathrm{Ni} / \mathrm{Pd} / \mathrm{CNF}$, in Fig. 2a, the position of the anodic peaks did not change with prolongation of sorption time [3, 14]. This indicates that mechanism of sorption/electrooxidation for the $\mathrm{EG} / \mathrm{Ni} / \mathrm{Pd} / \mathrm{C}$ composite remains probably unchanged with increasing sorption time.

\section{Conclusions}

Our investigations showed that it is possible to synthesize the multi-component composite $\mathrm{EG} / \mathrm{Ni} / \mathrm{Pd} / \mathrm{C}$. The investigated composite displays high electrochemical activity towards the processes of sorption/desorption of hydrogen. The amount of hydrogen accumulated within $\mathrm{EG} / \mathrm{Ni} / \mathrm{Pd} / \mathrm{C}$ enhances with the prolongation of potentiostatic sorption at $-1.2 \mathrm{~V}$. The electrochemical properties of the $\mathrm{EG} / \mathrm{Ni} / \mathrm{Pd} / \mathrm{C}$ composite are derivative of its composition, but its external layer, comprised of carbon fibers and most likely palladium carbide are of crucial importance in this.

Funding information This work was financially supported by the National Science Centre of Poland (2017/25/B/ST8/01634).

Open Access This article is distributed under the terms of the Creative Commons Attribution 4.0 International License (http:// creativecommons.org/licenses/by/4.0/), which permits unrestricted use, distribution, and reproduction in any medium, provided you give appropriate credit to the original author(s) and the source, provide a link to the Creative Commons license, and indicate if changes were made.
Publisher's note Springer Nature remains neutral with regard to jurisdictional claims in published maps and institutional affiliations.

\section{References}

1. Skowroński JM, Krawczyk P, Rozmanowski T, Urbaniak J (2008) Electrochemical behaviour of exfoliated $\mathrm{NiCl}_{2}$-graphite intercalation compound affected by hydrogen sorption. Energy Convers Manag 49:2440-2447

2. Skowroński JM, Rozmanowski T, Krawczyk P (2013) A Enhancement of electrochemical hydrogen storage in $\mathrm{NiCl}_{2}$ $\mathrm{FeCl}_{3}-\mathrm{PdCl}_{2}$-graphite intercalation compound effected by chemical exfoliation. Appl Surf Sci 275:282-288

3. Krawczyk P, Rozmanowski T, Osińska M (2017) Electrochemical sorption of hydrogen in exfoliated graphite/nickel/palladium composite. Int J Hydrog Energy 41:20433-20438

4. Ziemecki SB, Jones GAJ, Swartzfager DG et al (1985) Formation of interstitial pd-c phase by interaction of ethylene, acetylene, and carbon-monoxide with palladium. J Am Chem Soc 107:4547-4548

5. Simonov AN, Simonov PA, Parmon VN (2012) Formic acid electrooxidation over carbon-supported nanoparticles of nonstoichiometric palladium carbide. J Power Sources 217:291-295

6. Hashishin T, Tamaki J (2008) Au-Pd catalyzed growth of carbon nanofibers. Mater Chem Phys 111:54-58

7. Kang JH, Shin DH, Yun KN, Masud FA, Lee CJ, Kim MJ (2014) Super growth of vertically-aligned carbon nanofibers and their field emission properties. Carbon 79:149-155

8. Yang Y, Rosalie J, Bourgeois L et al (2005) Bulk synthesis of carbon nanostructures: hollow stacked-cone-helices by chemical vapor deposition. Mater Res Bull 43:2368-2373

9. Deck CP, Vecchio K (2005) Growth mechanism of vapor phase CVD-grown multi-walled carbon nanotubes. Carbon 43:26082617

10. Terrones M (2003) Science and technology of the twenty-first century: synthesis, properties, and Applications of Carbon Nanotubes. Annu Rev Mater Res 33:419-501

11. Zheng GB, Kouda K, Sano H, Uchiyama Y, Shi YF, Quan HJ (2004) A model for the structure and growth of carbon nanofibers synthesized by the CVD method using nickel as a catalyst. Carbon 42:635-640

12. Yamamoto T, Adachi M, Kawabata K (1998) Carbon in palladium catalysts: a metastable carbide. Appl Phys Lett 63:3020-3023

13. Grdeń M, Łukaszewski M, Jerkiewicz G, Czerwiński A (2008) Electrochemical behaviour of palladium electrode: oxidation, electrodissolution and ionic adsorption. Electrochim Acta 53: 7583-7598

14. Skowroński JM, Czerwiński A, Rozmanowski T, Rogulski Z, Krawczyk P (2007) The study of hydrogen electrosorption in layered nickel foam/palladium/carbon nanofibers composite electrodes. Electrochim Acta 52:5677-5684

15. Skowroński JM, Czerwiński A, Rozmanowski T et al (2009) The investigation on the mechanism of electrochemical hydrogen storage in sandwich nickel foam/palladium/carbon nanofibers electrodes. J Nanosci Nanotechnol 9:3858-3865 